\title{
Human adipose tissue-resident monocytes exhibit an endothelial-like phenotype and display angiogenic properties
}

Amparo Navarro ${ }^{1}$, Severiano Marín ${ }^{2}$, Nicasia Riol$^{3}$, Francisco Carbonell-Uberos ${ }^{3}$ and María Dolores Miñana ${ }^{1 *}$

\begin{abstract}
Introduction: Adipose tissue has the unique property of expanding throughout adult life, and angiogenesis is required for its growth. However, endothelial progenitor cells contribute minimally to neovascularization. Because myeloid cells have proven to be angiogenic, and monocytes accumulate in expanding adipose tissue, they might contribute to vascularization.
\end{abstract}

Methods: The stromal vascular fraction (SVF) cells from human adipose tissue were magnetically separated according to CD45 or CD14 expression. Adipose-derived mesenchymal stromal cells (MSCs) were obtained from SVF CD45 cells. $\mathrm{CD}_{14}^{+}$monocytes were isolated from peripheral blood (PB) mononuclear cells and then cultured with SVF-derived MSCs. Freshly isolated or cultured cells were characterized with flow cytometry; the conditioned media were analyzed for the angiogenic growth factors, angiopoietin-2 (Ang-2), vascular endothelial growth factor (VEGF), basic fibroblast growth factor (bFGF), hepatocyte growth factor (HGF), granulocyte colony-stimulating factor (G-CSF), and granulocyte macrophage colony-stimulating factor (GM-CSF) with Luminex Technology; their angiogenic capacity was determined in an in vivo gelatinous protein mixture (Matrigel) plug angiogenesis assay.

Results: $\mathrm{CD}^{+} 5^{+}$hematopoietic cells within the SVF contain CD14 $4^{+}$cells that co-express the CD34 progenitor marker and the endothelial cell antigens VEGF receptor 2 (VEGFR2/KDR), VEGFR1/Flt1, and Tie2. Co-culture experiments showed that SVF-derived MSCs promoted the acquisition of KDR and Tie-2 in PB monocytes. MSCs secreted significant amounts of Ang-2 and HGF, but minimal amounts of bFGF, G-CSF, or GM-CSF, whereas the opposite was observed for SVF CD14 $4^{+}$cells.

Additionally, SVF CD14+ cells secreted significantly higher levels of VEGF and bFGF than did MSCs. Culture supernatants of PB monocytes cultured with MSCs contained significantly higher concentrations of VEGF, HGF, G-CSF, and GM-CSF than did the supernatants from cultures without MSCs. Quantitative analysis of angiogenesis at 14 days after implantation demonstrated that neovascularization of the implants containing SVF CD $14^{+}$cells or PB monocytes previously co-cultured with MSCs was 3.5 or 2 times higher than that observed in the implants with SVF-derived MSCs. Moreover, immunofluorescence of Matrigel sections revealed that SVF CD $14^{+}$cells differentiated into endothelial cells and contributed to vascular endothelium.

Conclusions: The results from this study suggest that adipose tissue-resident monocytes should contribute to tissue vascularization. Because SVF CD14 $4^{+}$cells were more efficient in inducing angiogenesis than SVF-derived MSCs, and differentiated into vascular endothelial cells, they may constitute a new cell source for cell-based therapeutic angiogenesis.

\footnotetext{
* Correspondence: minyana_mdo@gva.es

${ }^{1}$ Regenerative Medicine Laboratory, Fundación Hospital General Universitario,

46014 Valencia, Spain

Full list of author information is available at the end of the article
} 


\section{Introduction}

Adipose tissue is composed of mature adipocytes and a heterogeneous stromal cell population surrounding them termed stromal vascular fraction (SVF) [1]. Adipose tissue is highly vascularized and has the unique property of expanding and regressing throughout adult life [2]. Although angiogenesis is required in growing adipose tissue, [3] the mechanisms of adipose vascularization are not fully understood. In past years, it has become evident that in addition to endothelial cell sprouting from preexisting blood vessels, endothelial progenitor cells and/or myeloid cells contribute to the angiogenic process $[4,5]$. However, in an in vivo adipogenesis model, endothelial progenitor cells minimally contributed to new vasculature, although the role of myeloid cells in adiposetissue angiogenesis was not investigated [6].

Adipogenesis and angiogenesis are two closely related processes during embryogenesis and in adult life $[2,7,8]$, and accumulating evidence demonstrates a functional link among endothelial cells, adipocytes, and monocytes. Conditioned media from adipose endothelial cells increases preadipocyte proliferation rates [9], whereas inhibition of vascular endothelial growth factor (VEGF)-VEGF receptor 2 (VEGFR2) signaling reduces angiogenesis and inhibits adipocyte differentiation [10]. Conditioned media from mature adipocytes induce overexpression of the intracellular adhesion molecule and platelet/endothelial cell adhesion molecule (PECAM)-1 in adipose endothelial cells, which in turn increases blood monocyte adhesion and migration to/through endothelial cells [11]. Moreover, mature adipocytes expressing monocyte chemoattractant protein-1, interleukin-8, and leptin are directly involved in this chemotactic effect [11]. Leptin, which is elevated in the plasma of obese subjects [12], increases blood monocyte adhesion and transmigration in a concentration-dependent manner [11] and also induces angiogenesis [13].

In expanding adipose tissue, monocytes accumulate proportional to the body mass index and adipocyte area $[11,14]$; therefore, it is tempting to speculate that monocytes may contribute to adipose tissue growth. Most efforts have been directed to the study of monocytes/ macrophages in the context of obesity [14-16]; therefore, little information exists regarding their possible angiogenic properties.

Therefore, to address this question, we characterized $\mathrm{CD}_{14}{ }^{+}$cells contained in the SVF from human adipose tissue and determined the ability of these tissue-resident monocytes to induce angiogenesis in an in vivo Matrigel plug assay. In this study, mesenchymal stromal cells (MSCs) derived from adipose SVF, known to be angiogenic in animal models of ischemia $[17,18]$, the nonhematopoietic $\mathrm{CD} 45^{-}$cell component of the SVF, and blood $\mathrm{CD}_{14}{ }^{+}$monocytes were used as controls in these investigations.

\section{Methods}

\section{Tissue sampling}

Human adipose tissue was obtained from female patients undergoing abdominal lipectomy at the University General Hospital of Valencia (Table 1 summarizes the clinical and laboratory characteristics of patients). Peripheral blood (PB) was obtained from adult healthy donors. The study was approved by the Clinical Research Ethics Committee of the Valencia University General Hospital, and patients and donors signed an informed consent.

\section{Cell isolation and culture}

Human adipose tissue SVF was obtained after enzymatic tissue digestion with collagenase, as previously described [19]. The SVF cells were magnetically labeled with antiCD45 or anti-CD14 microbeads (Miltenyi Biotec, $\mathrm{GmbH}$, Bergisch Gladbach, Germany), and cell populations were separated by using the MACS system (Miltenyi Biotec). Adipose-derived MSCs were obtained from the SVF $\mathrm{CD} 45^{-}$isolated cells. In brief, $\mathrm{CD} 45^{-}$cells were plated at a density of 30,000 cells $/ \mathrm{cm}^{2}$ in endothelial basal medium (EBM-2) supplemented with EGM-2MV SingleQuots containing VEGF, basic fibroblast growth factor (bFGF), insulin-like growth factor-1, epidermal growth factor, and 5\% FBS, (Lonza Walkersville, Inc., Walkersville, MD, USA). After reaching $80 \%$ to $90 \%$ confluence, adherent cells were detached by using $0.25 \%$ trypsinethylenediaminetetraacetic acid (EDTA) solution (Lonza) and reseeded at the same density. All of the studies were performed at the end of the second passage. PB mononuclear cells were obtained by centrifugation over Ficoll-Paque (Stem Cell Technologies SARL, Grenoble, France), and $\mathrm{CD} 14^{+}$monocytes were isolated by positive selection by using anti-CD14 microbeads and the MACS system (Miltenyi Biotec). CD $14^{+}$cells were cultured in EGM-2MV with or without MSCs. In brief, MSCs were resuspended in EGM-2MV to a concentration of $0.75 \times 10^{6}$ cells $/ \mathrm{ml}$ and transferred to 24 -well plates (100 $\mu \mathrm{l} /$ well). After 24 hours, $0.1 \times 10^{6}$ monocytes $\left(1 \times 10^{6}\right.$ cells $/ \mathrm{ml}$ ) were plated into the well (full-contact) or onto the membrane (0.4- $\mu \mathrm{m}$ pore size) of transwell cell-culture inserts (noncontact). At the indicated time points, monocytes were removed from the membrane by washing with phosphate-buffered saline (PBS) containing $1 \mathrm{~m} M$ EDTA or harvested together with MSCs by scraping and then analyzed with flow cytometry. All of the cell cultures were incubated at $37^{\circ} \mathrm{C}$ in a humidified $5 \% \mathrm{CO}_{2}$ atmosphere.

\section{Generation of cells-conditioned media}

PB mononuclear cells were divided in two parts; one half was used to isolate untouched monocytes by using an indirect magnetic labeling (Monocyte Isolation Kit II; Miltenyi Biotec), whereas the other half was used to obtain monocytes by positive selection. Each of the 
Table 1 Clinical characteristics of the study patients

\begin{tabular}{lcc}
\hline Variables & $<\mathbf{4 5}$ years $(\boldsymbol{n}=\mathbf{1 2})$ & $\mathbf{2 4 5}$ years $(\boldsymbol{n}=\mathbf{1 8})$ \\
\hline Sociodemographics & $34.7 \pm 5.3(24-39)$ & $53.7 \pm 5.1(46-64)$ \\
Age (years) & 100 & 100 \\
White (\%) & 33.3 & 50 \\
Habits & 8.3 & 0 \\
Smoking (\%) & 0 & 0 \\
Alcohol consumption (\%) & & $101.65 \pm 28.50(79-183)$ \\
Drugs consumption (\%) & $94.75 \pm 13.87(67-108)$ & $128.59 \pm 21.72(104-180)$ \\
Clinical characteristics & $128.33 \pm 11.29(111-138)$ & $70.53 \pm 7.06(58-82)$ \\
Glucemia (mg/dl) & $71.58 \pm 9.10(59-89)$ & 16.7 \\
Systolic BP (mm Hg) & 0 & 5.6 \\
Diastolic BP (mm Hg) & 8.3 & 5.6 \\
Diabetes (\%) & 0 & 16.7 \\
Hypertension (\%) & 0 & 5.6 \\
Hyperlipidemia (\%) & 8.3 & 5.6 \\
Diabetes treatment (\%) & 0 & \\
Antihypertensive treatment (\%) & & \\
Lipid-lowering treatment (\%) & & \\
\hline
\end{tabular}

$\mathrm{BP}$, blood pressure. Values are expressed as mean $\pm \mathrm{SD}$, or as percentages, when indicated. The range of values is given in parentheses.

selected monocyte populations was cultured for 72 hours in RPMI (Lonza) with 5\% autologous plasma (condition 1) or in EBM-2 with 2.5\% FBS (condition 2). Additionally, monocytes were cultured in EGM-2MV (condition 3) or in a transwell system with adipose-derived MSCs for 5 days. At the end of the culture period, monocytes were switched to EBM-2 with 2.5\% FBS, and 72 hours later, conditioned media were collected. Isolated SVF CD14 ${ }^{+}$ cells were divided in two parts: one was cultured as in condition 2, and the remaining cells, as in condition 3. Adipose-derived MSCs were grown in EGM-2MV until confluent, and then switched to EBM-2 with 2.5\% FBS. Seventy-two hours later, conditioned media were collected, centrifuged, and frozen at $-80^{\circ} \mathrm{C}$ until use. Conditioned media were analyzed for the angiogenic or antiapoptotic growth factors, angiopoietin-2 (Ang-2), VEGF, bFGF, granulocyte colony-stimulating factor (GCSF), granulocyte macrophage colony-stimulating factor (GM-CSF), and hepatocyte growth factor (HGF) with Luminex xMAP Technology by using a Luminex Screening Assay (R\&D Systems Minneapolis, MN, USA).

\section{Flow-cytometry analysis}

Cells were stained in PBS containing $1 \mathrm{~m} M$ EDTA and $1 \%$ bovine serum albumin (BSA) with specific antibodies or isotype-matched controls for 30 minutes at $4^{\circ} \mathrm{C}$ in the dark. After washing, cells were analyzed on a FACSCanto II (BD Biosciences, Erembodegem, Belgium) by using FACSDiva software (BD Biosciences). The antibodies used were CD9, CD13, CD14, CD31, CD34, CD45, CD144,
CD146, CD90, CD105 (BD Biosciences), VEGFR1/Flt-1 (clone 49560; R\&D Systems, Abingdon, UK), VEGFR2/ KDR (clone ES8-20E6 from Miltenyi Biotec and clone 89106 from R\&D Systems), and Tie2/Tek (clone 83715 from R\&D Systems and clone 33.1(Ab33) from BioLegend, Uithoorn, The Netherlands) conjugated to fluoresceinisothiocyanate (FITC), phycoerythrin (PE), allophycocyanin (APC), and PE-cyanin7 (PE-Cy7) or APC-cyanin7 (APC-Cy7). 7-Amino-actinomycin D (Sigma-Aldrich, Madrid, Spain) was used for removal of nonviable cells in the analysis.

\section{In vivo Matrigel plug assay}

Freshly isolated SVF $\mathrm{CD} 45^{+}, \mathrm{CD} 45^{-}$, or $\mathrm{CD} 14^{+}$cells, adipose-derived MSCs, and $\mathrm{PB} \mathrm{CD}_{1} 4^{+}$monocytes, freshly isolated or cocultured with MSCs in a transwell system $\left(1 \times 10^{6}\right.$ cells in $50 \mu \mathrm{l}$ PBS) were individually mixed with $400 \mu \mathrm{l}$ of growth-factor-reduced Matrigel (BD Biosciences) and injected subcutaneously into the dorsal flank of 8- to 12-week-old female Hsd:athymic nude-Foxn $1^{n u}$ mice (Harlan Laboratories, Udine, Italy). Matrigel with PBS alone was used as negative control. Matrigel plugs were removed on day 14, fixed in zinc fixative solution (BD Biosciences), and embedded in paraffin for hematoxylin and eosin (H\&E) staining or for immunohistochemistry. For the functional perfusion of neovessels in Matrigel, 10 minutes before the Matrigel plugs were harvested, FITC-dextran (MW 70,000, SigmaAldrich) was injected intravenously into the tail vein. The mice were killed by intraperitoneal sodium pentobarbital 
injection. All animal procedures were conducted in conformity with institutional guidelines in compliance with the Spanish guidelines for animal care (RD 1201/2005) and the European Community Council Directive (2010/ 63/UE), and were approved by the Council of Agriculture of the Valencian Regional Government and by the internal Committee for Ethics and Animal Research.

\section{Matrigel-plug immunohistochemistry and immunofluorescence}

Matrigel plugs in 5- $\mu \mathrm{m}$ deparaffined sections were reacted with primary rabbit polyclonal anti-human CD45 (1/1,000 dilution) or anti-endothelial nitric-oxide synthase (eNOS) (1/100 dilution) (Abcam, Cambridge, UK), or monoclonal rat anti-mouse CD31 (1/25 dilution, clone MEC13.3; BD Pharmingen). For CD45 and e-NOS, antigens were heatretrieved in Antigen Retrieval Solution (Dako, Glostrup, Denmark), and endogenous peroxidase activity blocked by using 3\% hydrogen peroxide in methanol. Sections were incubated at $4{ }^{\circ} \mathrm{C}$ overnight with the primary antibodies. Nonspecific protein-binding sites and endogenous mouse IgG were sequentially blocked by incubation in PBS containing $0.1 \%$ Triton X-100, $0.5 \%$ BSA, and 10\% fetal bovine serum (FBS) for 1 hour at room temperature (RT) followed by nonconjugated AffiniPure Fab Fragment goat anti-mouse IgGs (Jackson ImmunoResearch Laboratories, West Grove, PA, USA) for 2 hours at RT. Sections were then incubated with biotin-conjugated secondary antibodies and treated with streptavidin-horseradish peroxidase, and the reaction was developed by using 3,3'-diaminobenzidine (DAB) substrate (LSAB + System-HRP; Dako).

For CD31, after blocking of endogenous peroxidase activity, the sections were incubated with the primary antibody at RT for 1 hour followed by blocking of nonspecific protein and endogenous mouse IgG. Primary antibodies were detected by sequential incubation with biotinylated secondary antibodies, streptavidin-horseradish peroxidase, and DAB substrate (Anti-Ig HRP Detection Kit, BD Biosciences). All of the slides were counterstained with hematoxylin.

For double immunofluorescence, tissue sections were dewaxed, rehydrated, incubated in Antigen Retrieval Solution (BD Pharmingen), permeabilized with $0.2 \%$ Triton-X100 in PBS for 30 minutes, and blocked for 1 hour at RT with $1 \%$ BSA and 10\% normal goat serum (Jackson Immunoresearch Laboratories) in PBS. Sections were then immunostained with rabbit anti-human von Willebrand factor (vWF; 1/100 dilution, Sigma), rabbit anti-human nestin (1/250 dilution, Millipore, Temecula, CA, USA) or rabbit anti- $\alpha$-smooth muscle actin ( $\alpha$ SMA; $1 / 100$ dilution; Abcam), overnight at $4^{\circ} \mathrm{C}$, followed by goat anti-rabbit conjugated with Alexa 555 (Jackson Immunoresearch Laboratories). Then, to identify murine endothelial cells, slides were stained with rat anti-mouse CD31
(1/25 dilution, clone MEC13.3; BD Pharmingen) followed by goat anti-rat conjugated with Alexa 488 .

To identify human endothelial cells, slides were blocked with Carbo-Free blocking solution (Vector Laboratories, Burlingame, CA, USA) and stained with biotinylated Ulex europaeus agglutinin 1 (UEA-1; 1/100 dilution, Vector Laboratories) for 1 hour at RT followed by fluorescein (DTAF)-conjugated streptavidin (Jackson Immunoresearch Laboratories). The $\alpha \mathrm{SMA}$ and the $\mathrm{vWF}$ antibodies are cross-reactive for mouse and human. Images were acquired by using a Leica DFC480 camera and Leica DM6000 microscope with the Leica Application Suite (LAS), Version 3.6.0.

\section{Neovessel quantification in Matrigel plugs}

In H\&E-stained sections, newly formed vessels were defined as endothelium-lined tubular structures containing clearly identifiable erythrocytes. One in every five slides was counted, by using a $40 \times$ objective, in a blinded fashion, and the number of vessels per square millimeter was averaged. Five animals were used for each condition. The lumen area was determined by using Leica Application Suite, v4.0 software (Leica Microsystems, Wetzlar, Germany).

\begin{tabular}{|c|c|}
\hline Cells & Percentage mean \pm SD \\
\hline \multicolumn{2}{|l|}{ Crude SVF cells } \\
\hline CD45 & $19 \pm 11(n=30)$ \\
\hline CD34 & $48 \pm 20(n=30)$ \\
\hline \multicolumn{2}{|l|}{ SVF CD45 cells } \\
\hline CD34 & $70 \pm 20(n=30)$ \\
\hline \multicolumn{2}{|l|}{ SVF CD $45^{+}$cells } \\
\hline CD34 & $29 \pm 13(n=30)$ \\
\hline CD14 & $35 \pm 13(n=20)$ \\
\hline \multicolumn{2}{|l|}{ SVF CD $34^{+}$cells } \\
\hline CD90 & $90 \pm 9(n=20)$ \\
\hline CD13 & $77 \pm 17(n=10)$ \\
\hline CD31 & $22 \pm 11(n=20)$ \\
\hline \multicolumn{2}{|c|}{ SVF CD $45^{+} \mathrm{CD} 34^{+}$cells } \\
\hline CD14 & $64 \pm 17(n=12)$ \\
\hline \multicolumn{2}{|c|}{ SVF CD $45^{+}$CD $14^{+}$cells } \\
\hline CD34 & $55 \pm 13(n=20)$ \\
\hline CD31 & $66 \pm 16(n=10)$ \\
\hline KDR & $55 \pm 17(n=8)$ \\
\hline Tie-2 & $32 \pm 14(n=8)$ \\
\hline Flt-1 & $34 \pm 23(n=5)$ \\
\hline
\end{tabular}

Cell populations in the stromal vascular fraction were characterized with flow cytometry. Values indicate the percentage of cells expressing selected antigens within the SVF cell subsets. Results are expressed as mean \pm SD. 


\section{Statistical analysis}

The results were expressed as the mean \pm standard deviation. The data were analyzed by using GraphPad Prism Software 5.0 (GraphPad Software Inc., La Jolla, CA, USA). The comparisons among groups were analyzed in a one-way ANOVA followed by Bonferroni post hoc test and, when appropriate, by Student $t$ test. Differences were considered to be statistically significant at $P<0.05$.

\section{Results}

Hematopoietic cell population from the SVF contains CD14 cells expressing CD34 and displaying an endothelium-like phenotype

Human adipose tissue SVF reportedly contains a variable proportion of CD34 $4^{+}$cells $[1,19,20]$. Here, we demonstrate that $\mathrm{CD}_{3} 4^{+}$cells accounted for approximately $50 \%$ of SVF cells. Most CD $34^{+}$cells expressed CD90 and CD13, which was indicative of their mesodermal origin, and a lower proportion were positive for CD31 (Table 2). As expected,
CD $45^{-}$cells were abundant in the SVF, and the majority of these cells expressed CD34. Unexpectedly, we found that approximately $30 \%$ of the remaining $C D 45^{+}$hematopoietic cells also expressed CD34 (Table 2). In human $\mathrm{PB}, \mathrm{CD} 34$ is a marker of hematopoietic progenitors; thus, virtually all CD $34^{+}$cells exhibit little or no CD45 expression, lack expression of cell-surface markers that are associated with the CD45 $5^{+}$lineage [21] and are clustered in a discrete cell population when analyzed with flow cytometry (Figure 1A). However, approximately 65\% of CD $45^{+} \mathrm{CD}_{34}{ }^{+}$SVF cells co-expressed CD14 (Table 2; Figure 1B). Further analysis of the CD $45^{+}$SVF cells demonstrated that $35 \%$ of them expressed CD14, of which 55\% co-expressed CD34 (Figure 1B), whereas most of the remaining $\mathrm{CD} 45^{+}$cells identified the lymphocyte subset. Remarkably, most adipose $\mathrm{CD} 14^{+}$cells expressed CD31 and exhibited an endothelium-like phenotype, in contrast to what was observed in circulating CD14 ${ }^{+}$ monocytes, as demonstrated by KDR, Tie-2, and Flt1
A
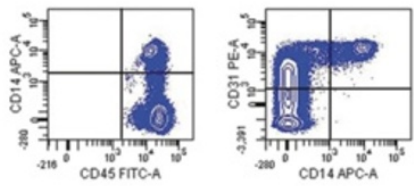

B
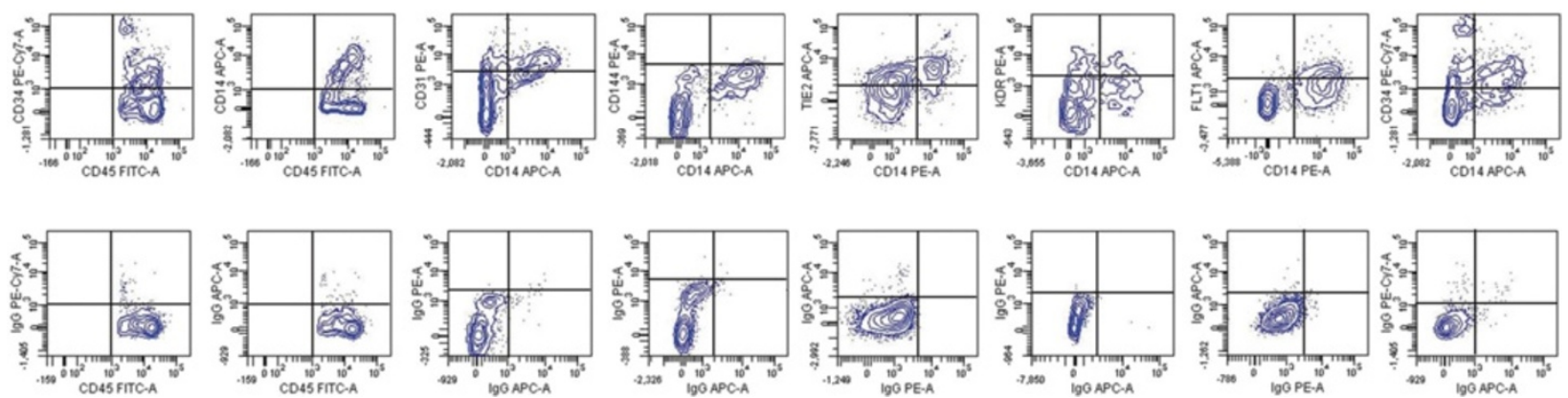

Figure 1 SVF CD14 ${ }^{+}$cells exhibit a proangiogenic phenotype. PB nucleated cells (A) were analyzed for CD45 and CD34 expression. Top right, $C D 34^{+} \mathrm{CD} 45^{\text {low }}$ cells corresponding to hematopoietic progenitor cells are shown. Bottom, CD45 cells (blue) were gated and analyzed for CD14 expression and for co-expression of CD14 with CD31, Tie2, KDR, Flt-1, and CD34. The CD14 ${ }^{+}$cells represented $20 \%$ of CD45 cells, which in turn accounted for $98.5 \%$ of the total viable PB nucleated cells. SVF cells (B) were analyzed for CD45 expression, and then the gated CD45 ${ }^{+}$cells (blue) were analyzed for CD34 and CD14 expression and for the co-expression of CD14 with CD31, CD144, Tie2, KDR, Flt-1, and CD34. Isotype-matched controls are shown. CD45 cells accounted for $6 \%$ of total viable cells. Dot plots of CD14 conjugated with APC or PE correspond to three different samples. 
co-expression (Table 2, Figure 1B), although CD144 expression was barely detected (Figure 1).

\section{Adipose-derived MSCs promote the expression of endothelial markers in circulating monocytes}

Because adipose stromal cells secrete a wide variety of angiogenic factors [22], circulating $\mathrm{CD}_{14}{ }^{+}$monocytes could acquire an endothelial cell phenotype after tissue recruitment. To test this hypothesis, PB CD14 ${ }^{+}$cells were cultured on a monolayer of adipose-derived MSCs, and the induced phenotypic changes were evaluated. As demonstrated in Figure 2A, SVF-derived MSCs had typical fibroblast morphology; expressed the mesodermal antigens CD9, CD13, CD90 and CD105; and lacked expression of CD31, CD34, VEGFR2/KDR and Tie-2 (Figure 2B). We observed that after 3 days in co-culture, approximately $40 \%$ (range, $20 \%$ to $50 \% ; n=4$ ) and $30 \%$ (range, $10 \%$ to $40 \% ; n=4$ ) of CD14 $4^{+}$monocytes expressed KDR and Tie-2, respectively (Figure $3 \mathrm{~B}$ ), and these cell proportions were maintained for the next 4 days. Of note, a similar level of induction was observed when CD14 ${ }^{+}$ monocytes were seeded into transwell membranes; thus, direct contact between monocytes and MSCs was not necessary to induce changes in their antigen-expression profile. As expected, no phenotypic changes were observed when $\mathrm{CD} 14^{+}$cells were cultured in endothelial growth medium, most likely because they were cultured on tissue-culture plastic (Figure 3B). However, CD34

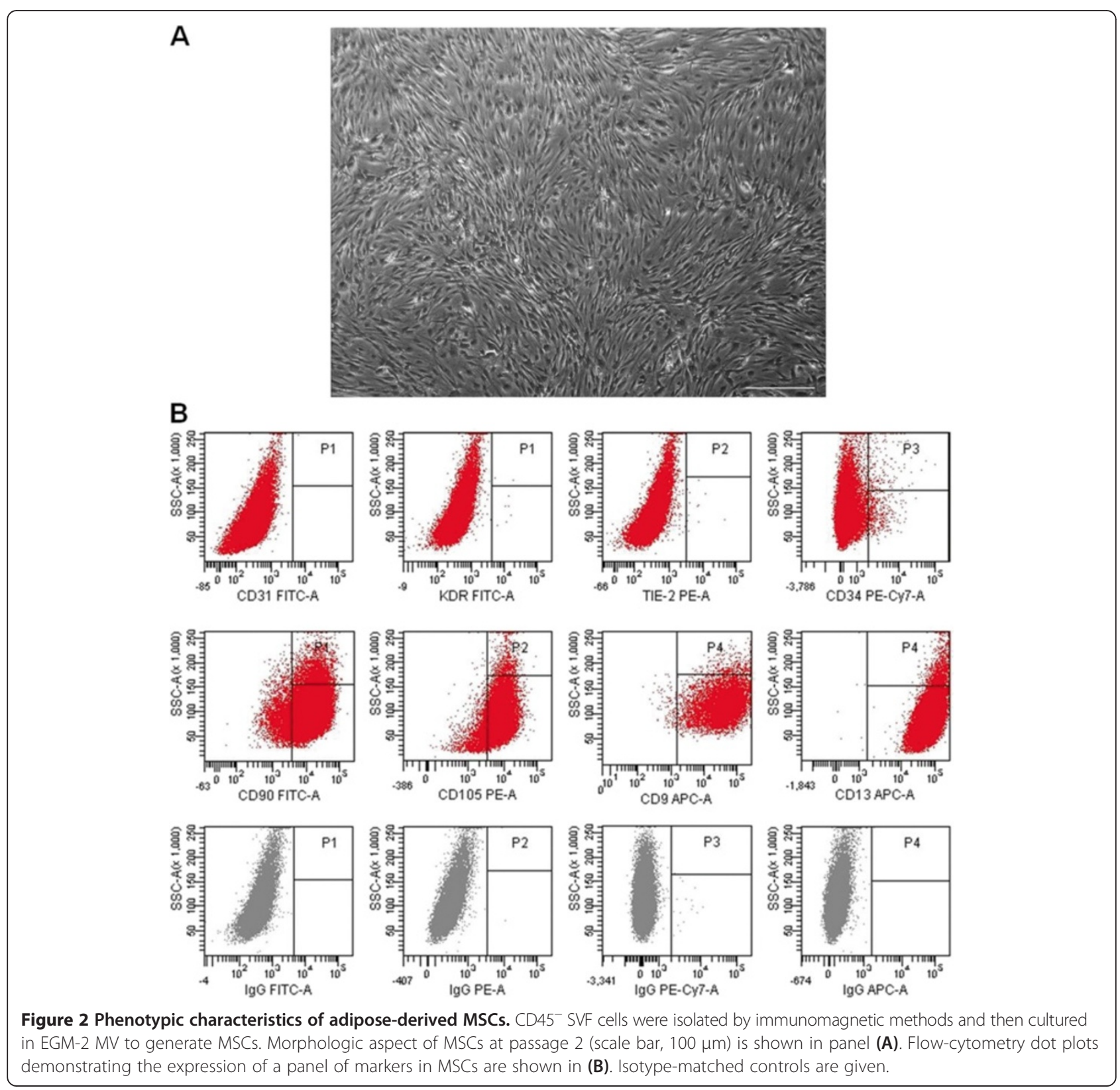


A

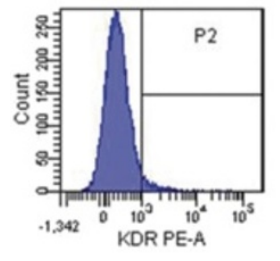

B

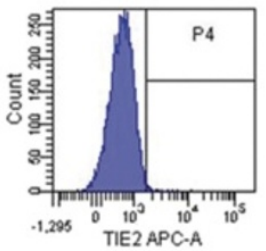

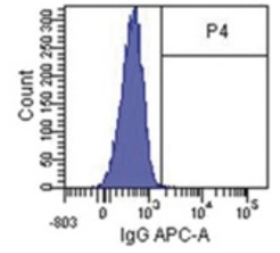

Monocytes cultured with MSC

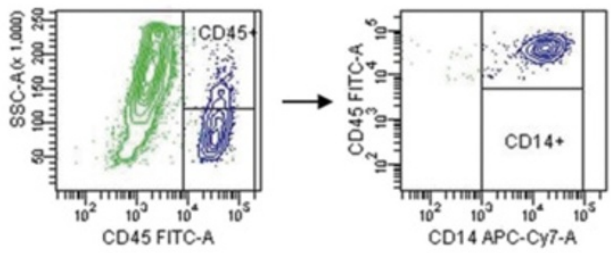

Monocytes in culture

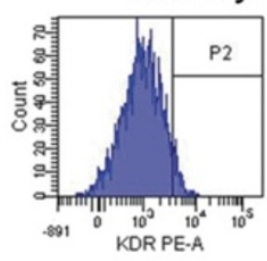

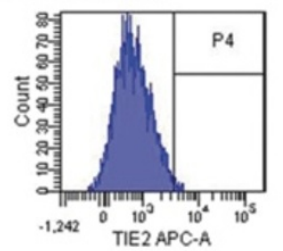

\section{Monocytes co-cultured with MSC}
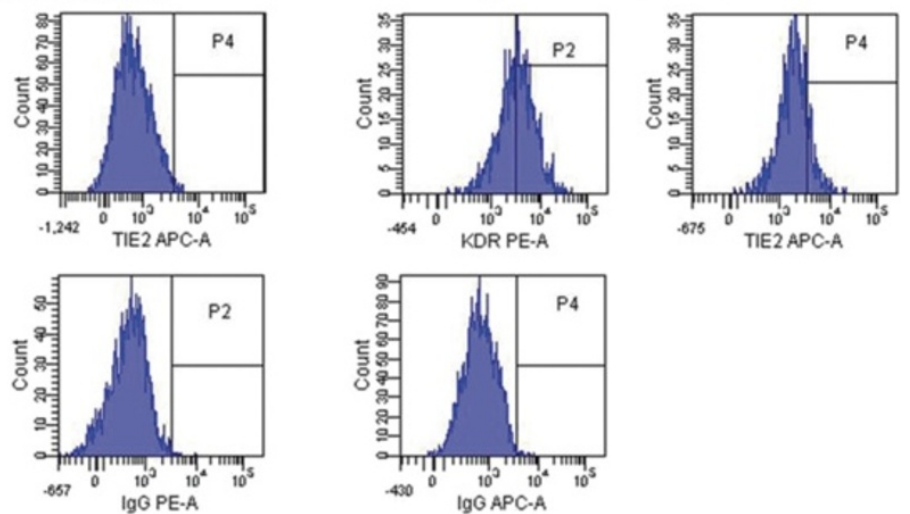

Figure 3 Induction of endothelial markers in circulating CD14 ${ }^{+}$cells. CD14 $4^{+}$monocytes were isolated from adult PB, cultured in EGM-2 MV with or without MSCS, and then analyzed with flow cytometry. Dot plots from freshly isolated CD14 $4^{+}$cells (A) and after 4 days of co-culture with adipose-derived MSCs (green) (B) are shown. Flow-cytometry histograms in panels A and B show the expression of KDR and Tie2 in gated CD14 cells. Isotype-matched controls are given.

expression was not induced in these culture conditions (data not shown).

\section{SVF CD14 ${ }^{+}$cells are highly angiogenic}

To determine the angiogenic capacity of hematopoietic cells contained in the SVF, we performed subcutaneous Matrigel implantation with SVF CD $45^{+}$cells and compared the resulting angiogenesis with that obtained by using SVF CD $45^{-}$cells and SVF-derived MSCs. Two weeks after implantation, the gross morphologic appearance of the explanted plugs revealed the induction of angiogenesis in Matrigel implants containing SVF-derived cells in contrast to the lack of angiogenesis that was observed with Matrigel alone (Figure 4A). Macroscopically, the neovessels induced by SVF cells were well organized and formed a dense capillary network, and some blood vessels with the appearance of arterioles were observed (Figure 4B). Histologic sections demonstrated the presence of blood vessels lined with endothelial cells of very different sizes that contained varying amounts of erythrocytes (Figure 4C,D). Interestingly, the number of neovessels formed in implants containing SVF CD $45^{+}$cells was higher (1.3-fold increase) than in those containing SVF CD45 cells or SVF-derived MSC, which was nearly 


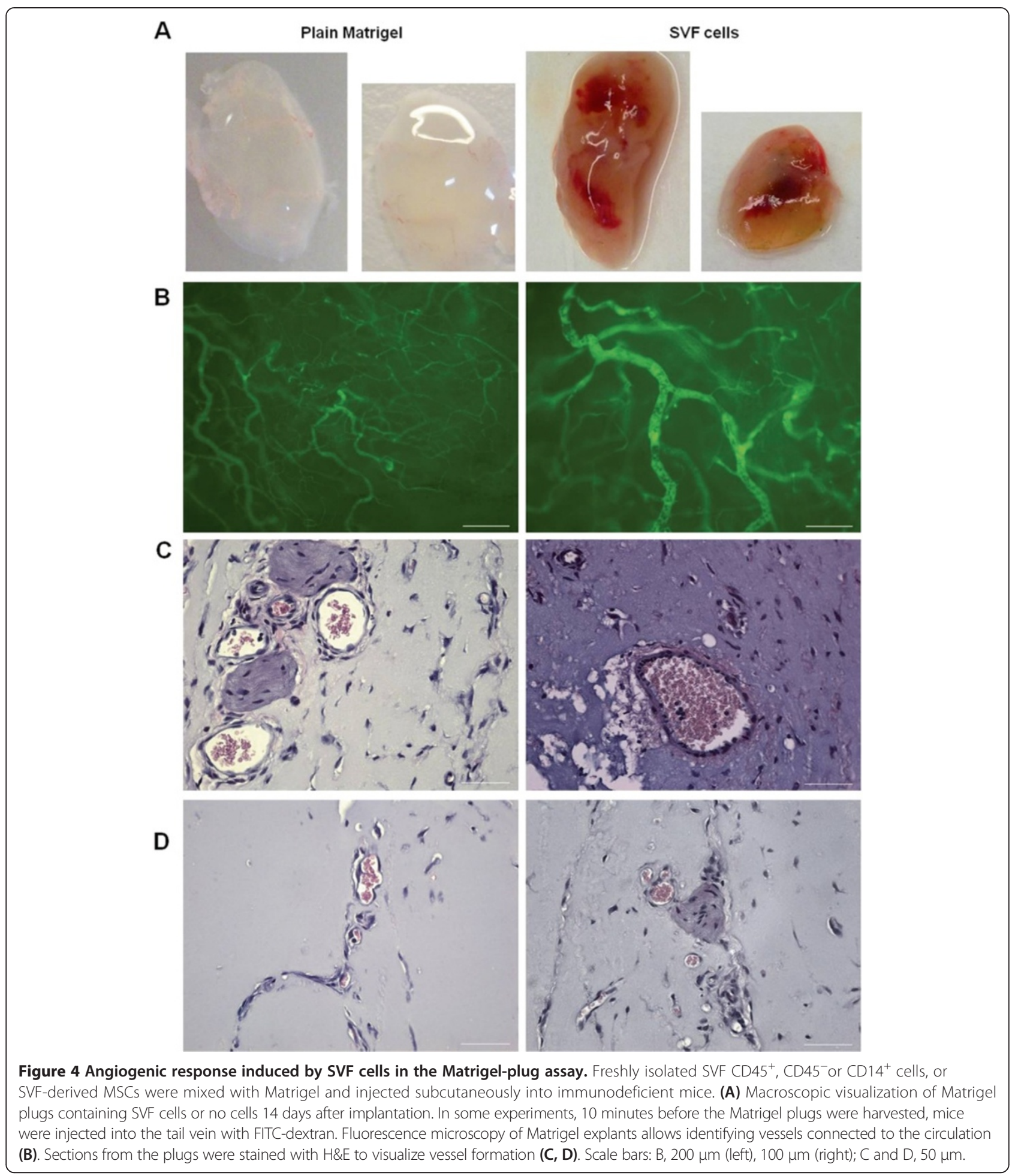

identical (Figure 5A). Nevertheless, no differences in size distribution were observed among vessels induced by SVF $\mathrm{CD} 45^{+}$cells and those induced by SVF CD45 cells or MSCs (Figure 5B). Although most Matrigel-implant neovessels were small vessels with a lumen area $\leq 150 \mu \mathrm{m}^{2}$, we also observed the development of a few very large blood vessels (lumen area ranging between 1,000 and 3,000 $\mathrm{m}^{2}$ ).

Given the cellular composition of the SVF CD $45^{+}$cell population, $\mathrm{CD} 14^{+}$cells must be the main cells responsible for the angiogenic activity observed. When isolated 


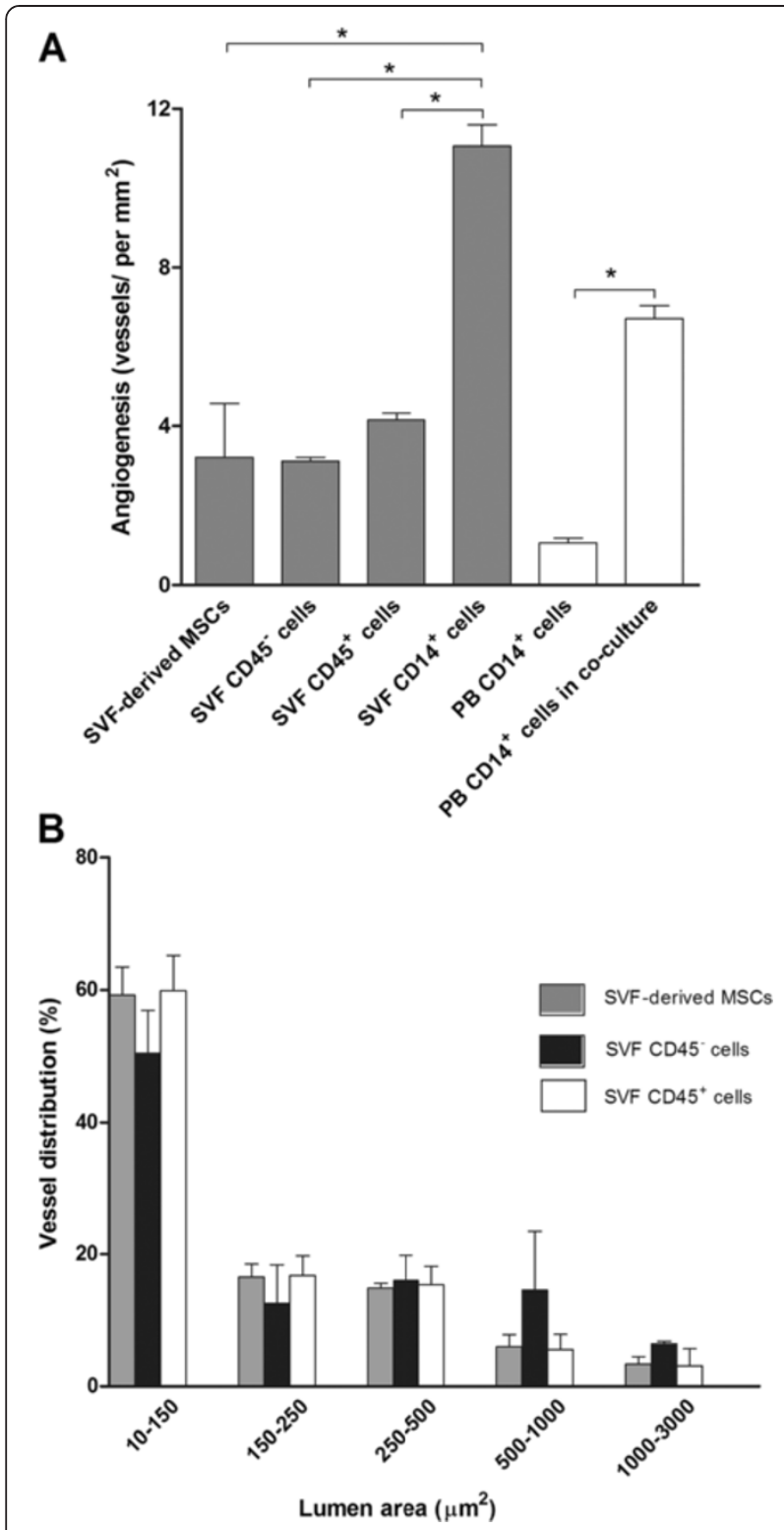

Figure 5 Quantification of neovessels in Matrigel plugs. Freshly isolated SVF cells, SVF-derived MSCs, and PB CD14 ${ }^{+}$monocytes, freshly isolated or after co-culture with SVF-derived MSCs in a transwell system, were individually embedded in Matrigel at $1 \times 10^{6}$ cells per implant. Matrigel explants were harvested 14 days after implantation and H\&E-stained sections were used to enumerate blood vessels (A). The lumen area of newly formed vessels in Matrigel implants containing SVF-derived MSCs or SVF-isolated $\mathrm{CD} 45^{+}$or $\mathrm{CD} 45^{-}$cells was determined. Vessel distribution indicates the percentage of vessels according to their lumen area, given as range of values (B). Results are expressed as the mean and SD of five Matrigel implants per test group. MSCs derived from three independent SVFs were used. ${ }^{*} P<0.0001$ for differences between groups linked by the brackets.

SVF CD14 ${ }^{+}$cells were injected, a robust angiogenesis was noticed; on a per-cell basis, the number of neovessels induced by SVF CD $14^{+}$cells was approximately 3.5 -fold increased when compared with that induced by SVFderived MSCs (Figure 5A). Finally, we tested whether the co-culture system led blood monocytes to increase their angiogenic capacity. As shown in Figure 5A, the number of neovessels in implants containing PB monocytes co-cultured with SVF-derived MSCs in a transwell system was 6 times higher than that obtained by using PB-isolated monocytes.

\section{SVF CD14 ${ }^{+}$cells secrete angiogenic factors}

To explore further the possibility that SVF CD14 ${ }^{+}$cells and PB monocytes that had been cultured with MSC promoted angiogenesis in a paracrine manner, we determined the levels of the angiogenic and antiapoptotic factors Ang-2, VEGF, bFGF, G-CSF, GM-CSF, and HGF in the conditioned media. We found that SVF CD14 ${ }^{+}$cells cultured in EGM-2MV secreted approximately threefold more VEGF and up to 16-fold more bFGF than the SVFderived MSCs cultured in the same medium. By contrast, a lesser secretion of Ang-2 was observed, and HGF was minimally secreted. Importantly, when SVF CD14 ${ }^{+}$cells were cultured in EBM-2, a medium that does not contain angiogenic factors, the level of secretion of VEGF and bFGF was increased approximately twofold, whereas that of G-CSF and GM-CSF was decreased by six- and twofold, respectively (Table 3 ). Next, to assess whether the type of selection used to isolate PB monocytes had affected their ability to secrete angiogenic factors, we obtained conditioned media from both positive selected monocytes and indirectly selected monocytes, termed untouched monocytes. As seen in Table 3, no differences were found in the secretion of growth factors studied between monocytes obtained by either of the two methods, in any of the culture media used. Nevertheless, untouched monocytes secreted higher amounts of G-CSF, and slightly lower levels of Ang-2, than positive selected monocytes when cultured in EBM-2 or EGM-2MV, respectively. When $\mathrm{PB} \mathrm{CD} 14^{+}$cells were co-cultured with MSCs, they were induced to secrete high levels of VEGF, and of G-CSF and GM-CSF, reaching values similar to those observed in SVF-derived MSCs, and SVF CD14 ${ }^{+}$cells cultured in EGM-2MV, respectively.

\section{SVF CD14 ${ }^{+}$cells incorporate into neovessels}

Neovessel recruitment and formation into the Matrigel plugs with SVF cells were also evaluated by staining with anti-mouse CD31 antibody. Because nude mice were used for in vivo angiogenesis assay, the explanted plugs did not demonstrate inflammatory reactions, and cells expressing CD31 must correspond to host endothelial cells. The majority of the endothelial cells lined together and formed blood vessels (Figure 6A). To investigate the contribution of the SVF CD14 ${ }^{+}$cells to the establishment of a vascular network in Matrigel plugs, sections were 
Table 3 Secretion of growth factors by SVF-derived MSC, SVF CD14 ${ }^{+}$cells, and PB monocytes

\begin{tabular}{|c|c|c|c|c|c|c|}
\hline & Ang-2 & VEGF & HGF & bFGF & G-CSF & GM-CSF \\
\hline SVF-derived MSCs & $1,642 \pm 1,157$ & $329 \pm 69$ & $12,602 \pm 1,492$ & $21 \pm 3$ & $70 \pm 13$ & $3.2 \pm 1.2$ \\
\hline \multicolumn{7}{|c|}{ PB-positive selected monocytes } \\
\hline Condition 1 & $200 \pm 35$ & $40 \pm 5$ & $7 \pm 1$ & $12 \pm 5$ & $0.6 \pm 0.2$ & $1.9 \pm 0.2$ \\
\hline Condition 2 & $186 \pm 78$ & $52 \pm 25$ & $20 \pm 19$ & $12 \pm 2$ & $7.4 \pm 2.2$ & $15 \pm 4$ \\
\hline Condition 3 & $278 \pm 18$ & $48 \pm 15$ & $137 \pm 35$ & $25 \pm 2$ & $3.4 \pm 1.2$ & $5 \pm 2$ \\
\hline Co-cultured with MSCs & $26 \pm 9^{*}$ & $210 \pm 49$ & $155 \pm 71^{*}$ & $34 \pm 4$ & $4,188 \pm 2,001^{*}$ & $957 \pm 552^{*}$ \\
\hline \multicolumn{7}{|c|}{ PB-untouched monocytes } \\
\hline Condition 1 & $229 \pm 36$ & $46 \pm 36$ & $9 \pm 1$ & $11 \pm 2$ & $0.7 \pm 0.3$ & $1.5 \pm 0.7$ \\
\hline Condition 2 & $215 \pm 142$ & $54 \pm 43$ & $28 \pm 23$ & $16 \pm 6$ & $33 \pm 7^{\dagger}$ & $18 \pm 8$ \\
\hline Condition 3 & $216 \pm 25^{\dagger}$ & $61 \pm 16$ & $163 \pm 75$ & $18 \pm 3$ & $4.7 \pm 1.4$ & $4.3 \pm 1.7$ \\
\hline Co-cultured with MSCs & $25 \pm 9^{*}$ & $197 \pm 96$ & $134 \pm 47^{*}$ & $27 \pm 5^{+}$ & $4,321 \pm 2,529^{*}$ & $878 \pm 514^{*}$ \\
\hline \multicolumn{7}{|l|}{ SVF CD14 ${ }^{+}$cells } \\
\hline Condition 2 & $220 \pm 123^{*}$ & $1,733 \pm 193^{*}$ & $18 \pm 8^{*}$ & $580 \pm 199^{*}$ & $30,895 \pm 6,699^{*}$ & $4,017 \pm 791^{*}$ \\
\hline Condition 3 & $176 \pm 96^{* \neq}$ & $916 \pm 164^{* \dagger}$ & $13 \pm 4^{* \neq}$ & $341 \pm 121^{* 1 \neq}$ & $5,555 \pm 3,986^{* \dagger}$ & $1,782 \pm 1,001^{*}$ \\
\hline
\end{tabular}

Cells derived from adipose tissue or PB monocytes were cultured as described in Methods, and the 72-hours conditioned media were analyzed by Luminex Screening Assays to determine the secretion of selected growth factors. Condition 1, RPMI with autologous plasma; condition 2, EBM-2 with FBS; and condition 3, EGM-2MV with FBS and then switched to EBM-2 with FBS. Values are expressed as mean \pm SD pg of the secreted factor normalized to $10^{6}$ cells. SVF from six different donors were used to generate MSCs. SVF CD14 ${ }^{+}$cells were isolated from the same SVF samples; PB monocytes were obtained from four different donors, and were co-cultured with MSCs derived from four different donors. Statistical significance: SVF CD14 ${ }^{+}$cells or PB monocytes versus SVF-derived MSCs, ${ }^{*} P<0.0001 ;$ SVF CD14 ${ }^{+}$cells cultured in condition 2 versus SVF CD14 ${ }^{+}$cells cultured in condition 3, and PB-positive selected monocytes versus PB untouched monocytes: cultured in condition 2 or cultured in condition $3,{ }^{\dagger} P<0.0001 ;$ SVF CD14 ${ }^{+}$cells versus PB monocytes co-cultured with MSCs, ${ }^{\ddagger} P<0.0001$.

stained with anti-human CD45. Figure 6B demonstrates that most $\mathrm{CD} 45^{+}$cells were localized near or surrounding blood vessels. However, in random Matrigel-explant sections, we noticed the presence of arterioles, as defined by their structure (presence of smooth muscle cells within the wall), that contained $\mathrm{CD} 45^{+}$cells adjacent to the endothelium (Figures $4 \mathrm{C}$ and $6 \mathrm{~B}$ ).

Last, sections were stained with anti-human e-NOS (Figure 6C). As expected, most vascular structures stained positive for e-NOS, and the pattern of staining was similar to that observed for CD45.

\section{SVF CD14 ${ }^{+}$cells differentiate into endothelial cells}

The better to determine the contribution of SVF CD14 $4^{+}$ cells to Matrigel vasculature, we analyzed for expression of Ulex europaeus-I lectin (UEA-I), which is specific for human vascular endothelium. Immunofluorescence analysis of consecutive Matrigel sections against mCD31 and UEA-1 showed a virtually identical staining pattern (Figure 7A,B). These findings demonstrate that SVF CD $14^{+}$cells give rise to endothelial cells, but additionally, that Matrigel implants were vascularized by blood vessels formed both from host-derived endothelial cells and from SVF CD14 ${ }^{+}$human cells. Co-staining for $\alpha \mathrm{SMA}$, which identifies human and murine perivascular cells, showed that vessel structures were composed of endothelial cells (green) closely associated with perivascular $\alpha \mathrm{SMA}^{+}$cells (red), the typical structure of mature blood vessels. However, immunostained sections demonstrated that Matrigel implants also contained vascular tubelike structures composed of $\alpha \mathrm{SMA}^{+}$cells, but devoid of $\mathrm{mCD} 31^{+}$or UEA-1-positive endothelial cells (Figure 7), probably indicating the presence of immature blood vessels, as previously reported [23].

Staining with anti-vWF to identify blood vessels of human and murine origin, demonstrated that Matrigel implants contained a significant number of vWF-positive cells, which were not associated with Matrigel vasculature (Figure 8A,B). Macrophages contribute to uptake of vWF [24] and are recruited into Matrigel implants supplemented with FGF-2 [25]. Here, we used nonsupplemented Matrigel implants and nude mice, but it is possible that FGF secreted by SVF CD $14^{+}$cells contributes to host-derived macrophage recruitment. Alternatively, vWF-positive cells could also identify SVF CD $14^{+}$cells contained in the implant.

Macrophages expressing the early pericyte marker NG2 proteoglycan have been shown to contribute to neovessel formation [23]. Therefore, to assess whether SVF CD14 ${ }^{+}$ cells displayed human pericyte markers, we performed immunostaining of human nestin, which is expressed in pericytes [26] and also in endothelial cells of newly formed blood vessels [27]. Although the expression of nestin was very weak, this was restricted to endothelial cells (Figure 8C,D), and we did not observe nestinpositive cells in the perivascular area. However, single nestin-positive cells (indicated by arrow in Figure 8C) were observed. 

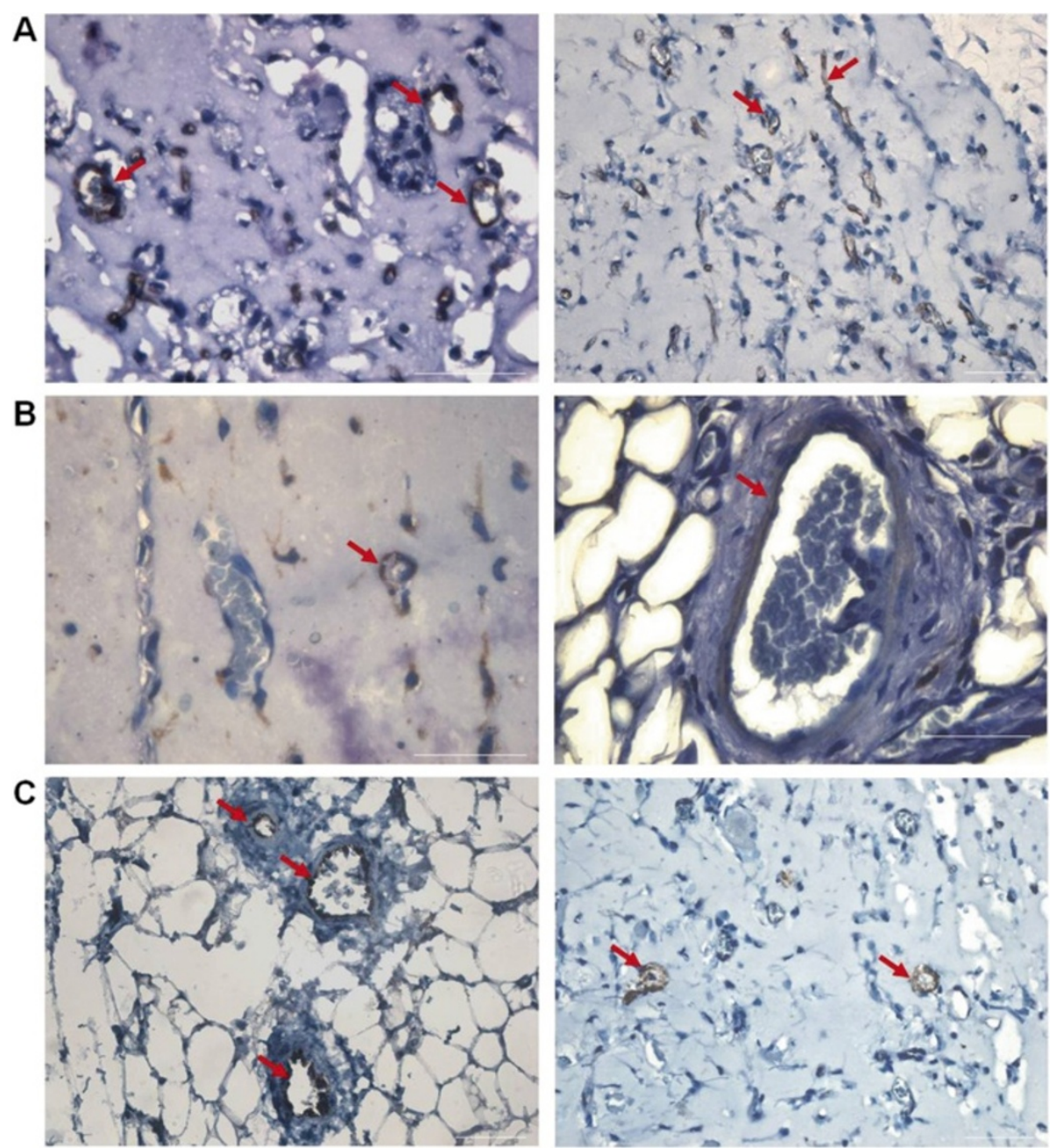

Figure 6 SVF CD14 ${ }^{+}$cells incorporate into new vessels. Fourteen days after implantation, Matrigel implants containing SVF CD $14^{+}$cells were evaluated for the expression of CD31, CD45, and e-NOS. (A) Representative images for CD31 staining. Arrows indicate the presence of CD31 ${ }^{+}$endothelial cells in the vessels formed. (B) Human CD45 immunostaining. Note that $C D 45^{+}$cells are located surrounding blood vessels (left) or adjacent to the endothelium (right). (C) Human e-NOS immunostaining. Arrows indicate positive staining of some blood vessels for e-NOS. Scale bars: A, 50 m; B, $50 \mu \mathrm{m}$ (left), $30 \mu \mathrm{m}$ (right); C, $50 \mu \mathrm{m}$.

\section{Discussion}

Adipose tissue, similar to bone marrow, contains stromal cells that secrete multiple angiogenic factors [22], and delivery of these cells has angiogenic therapeutic potential [28]. Herein we demonstrated that the hematopoietic cell population contained in the SVF is highly enriched in $\mathrm{CD} 45^{+} \mathrm{CD} 14^{+}$cells expressing CD34 antigen and an endothelium-like phenotype. Because CD34 is lost during leukocyte maturation, these $\mathrm{CD} 14^{+} \mathrm{CD} 34^{+}$cells must represent a population of immature monocytes. Similarly, several groups have demonstrated the existence of a small subset of circulating $\mathrm{CD} 14^{+}$monocytes that exhibit stem/progenitor cell properties. Kuwana et al. [29] cultured $\mathrm{CD} 14^{+}$cells on fibronectin without angiogenic factors and identified a population of $\mathrm{CD} 14^{+} \mathrm{CD} 45^{+} \mathrm{CD} 34^{+}$ monocytes with fibroblast-like morphology and the ability to differentiate into several mesodermal lineages. Kuwana et al. then demonstrated downregulation of CD14 and CD45 in this specific subset of monocytes when cultured in endothelial media; differentiation into endothelial cells expressing CD31, CD144, VEGFR1, VEGFR2, Tie-2, von Willebrand factor, e-NOS, and CD146; and vasculogenic properties in vivo [30]. Conversely, by using a highly sensitive antibody-conjugated magnetofluorescent liposomal technique, Romagnani et al. [31] demonstrated that a variable $\mathrm{CD} 14^{+}$cell proportion coexpressed CD34. These $\mathrm{CD} 14^{+} \mathrm{CD} 34^{\text {low }}$ cells, in contrast to fully differentiated $\mathrm{CD} 14^{+} \mathrm{CD} 34^{-}$monocytes, exhibited high expression of the embryonic stem cell markers Nanog and Oct- 4 and proliferated in the presence of early-acting hematopoietic cytokines. Because $\mathrm{CD} 14^{+} \mathrm{CD} 34^{\text {low }}$ staining identified the majority of circulating $\mathrm{KDR}^{+}$cells that differentiated 

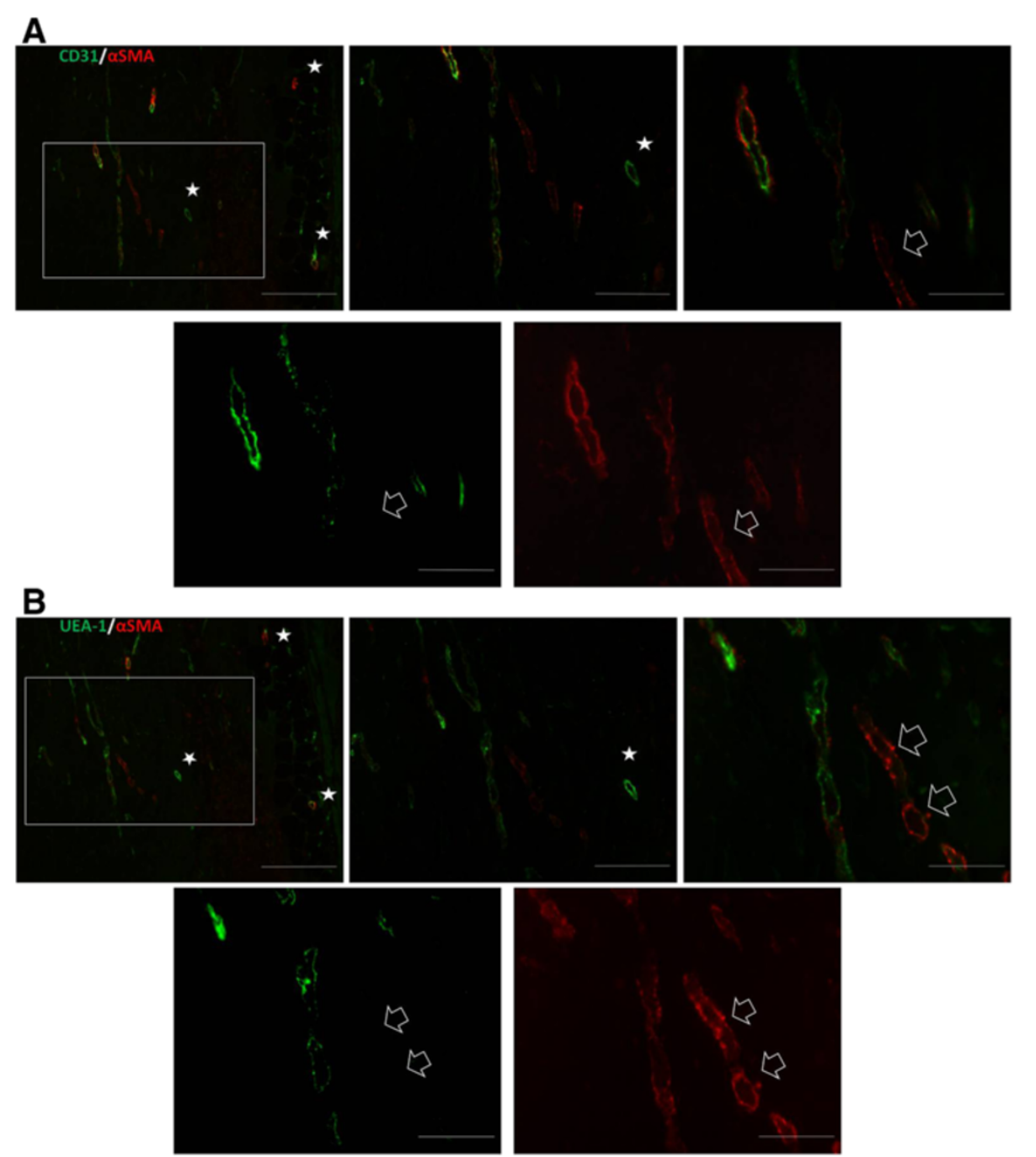

Figure 7 Matrigel implants contain blood vessels comprising human and mouse endothelial cells. Consecutive sections of Matrigel implants with SVF CD14 ${ }^{+}$cells were double-immunostained with antibodies against mCD31 (green) and aSMA (red) (A), or Ulex europaeus agglutinin 1 (UEA-1; green) and aSMA (red) (B). The images on the top of the panels A and B show merged images and correspond to the same microscopic field at different magnifications: left, low magnification; middle, medium magnification; right, higher magnification. Images on the bottom (A, B) show green and red fluorescence and correspond to the merged image at the highest magnification. Images in panel B correspond to a consecutive section. The insets in $\mathbf{A}$ and $\mathbf{B}$ (upper left) show the field at low magnification and asterisks illustrate benchmarks. Note that the green staining associated with murine (A) or human (B) endothelial cells in the adjacent sections is near identical. Double labeling shows a close assembly of aSMA-positive cells to the blood vessels. White arrows indicate aSMA-positive cells lining vascular-like structures which do not express murine (A) or human (B) endothelial cells. Scale bars in A, B (upper left): $200 \mu \mathrm{m}$, upper in the middle: $100 \mu \mathrm{m}$; upper right and bottom: $50 \mu \mathrm{m}$.

into mature endothelial cells [31], these cells may be the main source of PB-derived endothelial cells. However, $\mathrm{CD} 45^{+} \mathrm{CD} 34^{+}$cells in human ovarian tumors reportedly share monocyte and endothelial cell phenotypic characteristics and also have the ability to generate blood vessels in vivo [32].

Our results show that SVF CD14 ${ }^{+}$cells induced a robust angiogenesis in vivo in the murine Matrigel plug assays, significantly higher than that induced by SVF-derived MSCs, and more important, they differentiated into fully functional endothelial cells, thereby contributing to
Matrigel vasculature. Blood monocytes exit the circulation at a low frequency, migrate between vascular endothelial cells, and enter tissues. Among the several molecules involved in this process, PECAM-1/CD31 can drive the transmigration of a small subset of immature $\mathrm{CD} 14^{+} \mathrm{CD} 34^{+}$ monocytes by creating a haptotactic gradient [33] in the absence of chemokines [34]. Therefore, the physiological characteristics of adipose tissue [11] could favor recruitment of $\mathrm{CD} 14^{+} \mathrm{CD} 34^{+}$monocytes, which are modulated toward an endothelium-like phenotype because they are in a highly angiogenic microenvironment $[3,22]$. 

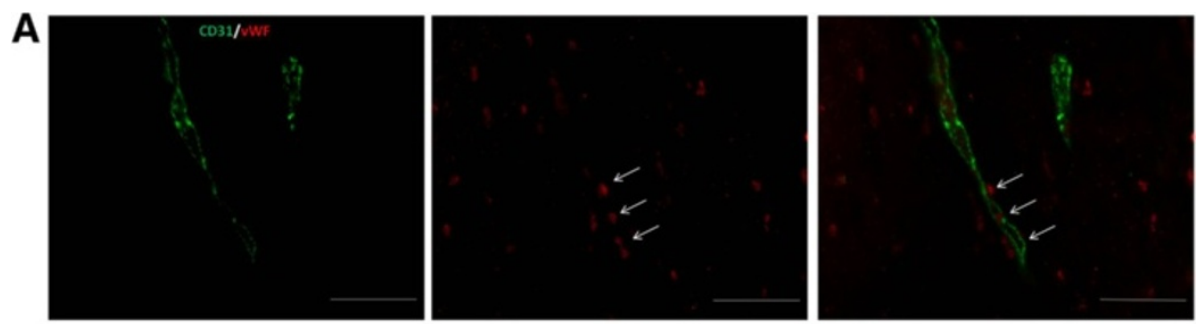

B
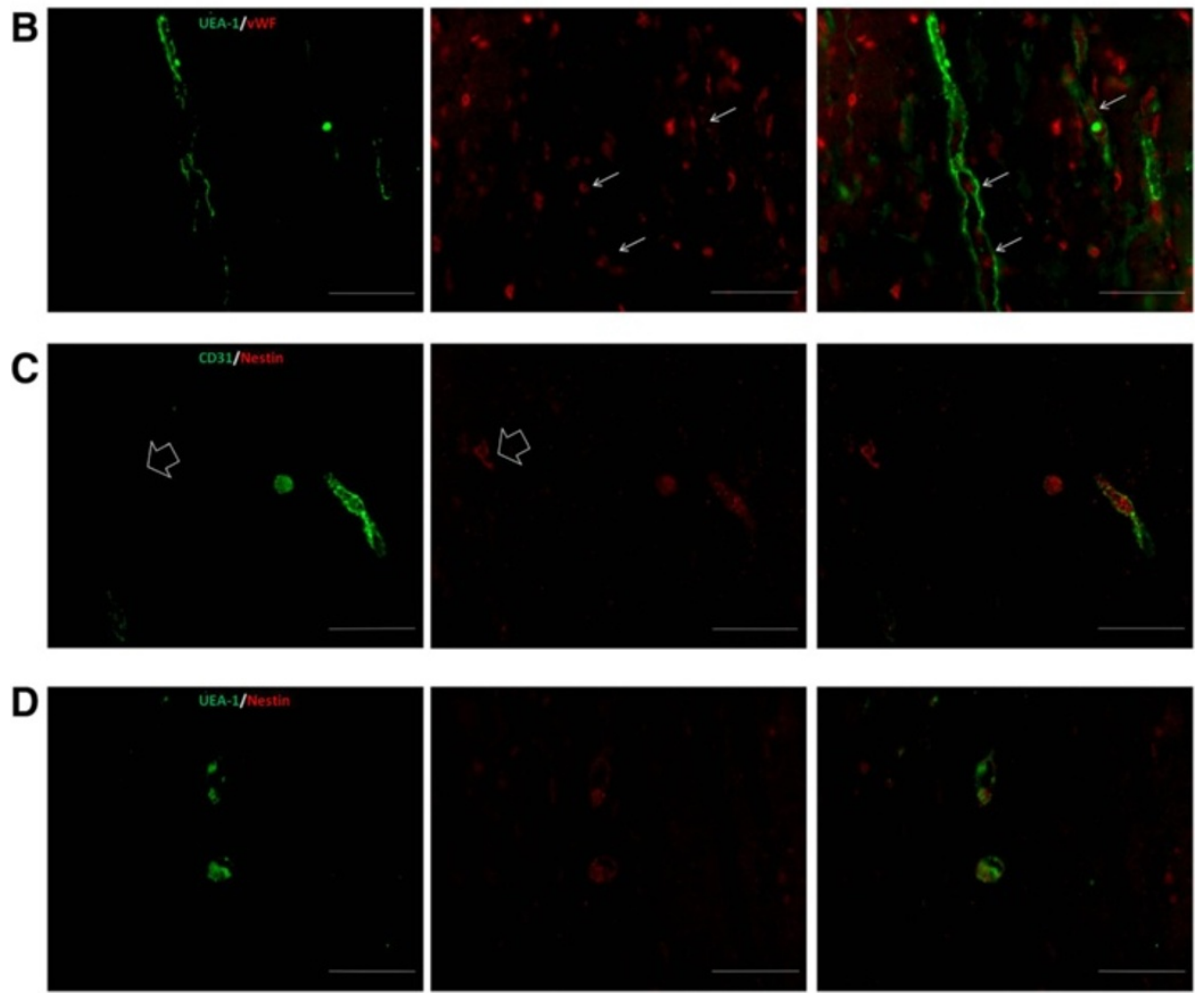

Figure 8 Immunofluorescence detection of nestin in Matrigel implants. Representative images of consecutive sections of Matrigel implants with SVF CD14 ${ }^{+}$cells stained by anti-mouse CD31 (green) and anti-VWF (red) (A), and by UEA-1 (green) and anti-VWF (red) (B). The arrows show colocalization of vWF-positive cells and endothelial cells of murine or human origin. However, in Matrigel implants, other vWF-positive cells not associated with blood vessels are shown. Double-immunofluorescence staining of human nestin (red) and mCD31 (green) (C), and human nestin (red) and UEA-1 (green) (D). In Matrigel implants, nestin was expressed in human and murine endothelial cells, although some nestin-positive cells (arrow) lacking mCD31 were observed. Scale bar, $50 \mu \mathrm{m}$.

According to this hypothesis, coculture experiments with circulating PB monocytes, together with SVF-derived MSCs, showed that MSCs promoted the acquisition of the endothelial markers KDR and Tie-2 in monocytes. But, importantly, these endothelium-like monocytes were highly angiogenic, and so the number of neovessels formed in implants containing these "transformed" monocytes was significantly increased when compared with those containing isolated PB monocytes or SVFderived MSCs by approximately 6 or 2 times, respectively.

Since Asahara et al. [35] described the presence of circulating endothelial progenitor cells, many efforts have been devoted to identify and characterize these cells because they represent a potential therapeutic option for improving neovascularization [36]. However, many reports have indicated that these bone marrow-derived cells are mostly of myeloid origin [37]. Furthermore, in blood, VEGFR2 and/or Tie2 expression was mainly restricted to monocytes, and only cells expressing either of these antigens contributed to endothelialization of balloon-injured femoral arteries in mice [38]. It was recently demonstrated that common myeloid and granulocyte progenitor populations also have angiogenic properties [39]. Myeloid cells participate in physiological angiogenesis and in pathological processes [38,40-42], and in the cancer field, different myeloid cell populations have been shown to regulate tumor angiogenesis [43].

Although controversy still exists regarding whether myeloid cells are incorporated into newly formed vessels, elegant experiments by Grunewald et al. [44] demonstrated 
that VEGF alone was sufficient to recruit myeloid cells in specific organs, and once retained in the perivasculature, these cells induced in situ proliferation of resident endothelial cells through a repertoire of angiogenic activity.

Among the growth factors and cytokines with angiogenic activity, much attention has been paid to angiogenesis induced by VEGF and bFGF [23]. Results reported here show that these two angiogenic factors were highly secreted by SVF CD14 ${ }^{+}$cells, even in amounts significantly greater than those secreted by MSCs. Because HGF was highly secreted by MSCs, unlike what was observed in SVF CD14 $4^{+}$cells, HGF must play an important role in angiogenesis induced by MSCs. Although unanimity occurs on the angiogenic properties of G-CSF [45], some controversy exists about whether GM-CSF induces or inhibits angiogenesis [46]. However, when GM-CSF was administered together with G-CSF, angiogenesis was increased [47]. Therefore, it is possible that the secretion of G-CSF and GM-CSF by SVF CD $14^{+}$cells stimulates Matrigel angiogenesis.

Moreover, it was recently reported that Ang-2, a regulator of vessel maturation [48], can function as a vessel-destabilizing or as a proangiogenic molecule in endothelial cells, depending on whether endothelial cells express Tie2 or not [49]. However, from the experiments performed in this work, it is difficult to establish the role of Ang-2 in this in vivo angiogenesis assay.

Overall, our results show that SVF CD14 ${ }^{+}$cells differentiated into fully functional vascular endothelial cells, and promoted angiogenesis through a paracrine manner, suggesting that tissue-resident $\mathrm{CD} 14^{+}$monocytes must contribute to adipose tissue angiogenesis. Moreover, the results highlight the role of stroma in modulating the angiogenic capacity of monocytes recruited. Indeed, MSCs, in a paracrine manner, induced changes in both antigen expression and secretion ability of growth factors in PB monocytes, which could explain their higher angiogenic capacity.

SVF from human adipose tissue has emerged as a source of MSCs for regenerative medicine [40,50]. However, we show, as proof of concept, that angiogenesis induced by SVF CD14 ${ }^{+}$cells is superior to that induced by SVF-derived MSCs. We think these findings are relevant for novel angiogenic therapies based on the use of SVF CD14+ ${ }^{+}$cells.

\section{Conclusions}

The results from this study demonstrate that SVF from human adipose tissue contains $\mathrm{CD} 14^{+}$cells expressing CD34, CD31, KDR, Tie-2, and Flt-1. In the Matrigel-plug assay, these endothelium-like $\mathrm{CD}_{1} 4^{+}$cells secreted high amounts of angiogenic factors, induced angiogenesis more efficiently than SVF-derived MSCs, differentiated into endothelial cells, and contributed to Matrigel vasculature.
Although angiogenesis is required in growing adipose tissue [9], the mechanisms of adipose tissue vascularization are not fully understood. The present data provide evidence that adipose tissue-resident monocytes might contribute to new vasculature. MSCs from adipose tissue are gaining interest for angiogenic therapies, as these cells are easily isolated. Our findings suggest that CD14 ${ }^{+}$ cells isolated from the SVF may augment the efficacy of therapeutic angiogenesis induced by SVF-derived MSCs, and could potentially be used alone to promote tissue vascularization.

\section{Abbreviations}

Ang-2: Angiopoietin-2; APC: allophycocyanin; APC-Cy7: allophycocyanin-cyanin7; bFGF: basic fibroblast growth factor; BSA: bovine serum albumin; DAB: 3, 3'-diaminobenzidine; EDTA: ethylendiaminetetraacetic acid; eNOS: endothelial nitric-oxide synthase; FBS: fetal bovine serum; FITC: fluorescein-isothiocyanate; G-CSF: granulocyte colony-stimulating factor; GM-CSF: granulocyte macrophage colony-stimulating factor; H\&E: hematoxylin and eosin; HGF: hepatocyte growth factor; MSCs: mesenchymal stromal cells; PB: peripheral blood; PBS: phosphatebuffered saline; PE: phycoerythrin; PECAM-1: platelet/endothelial cell adhesion molecule-1; PE-Cy7: phycoerythrin-cyanin7; RT: room temperature; SVF: stromal vascular fraction; UEA-1: Ulex europaeus agglutinin 1; VEGF: vascular endothelial growth factor; VEGFR2: vascular endothelial growth factor receptor 2; vWF: von Willebrand factor; a-SMA: a-smooth muscle actin.

\section{Competing interests}

The authors declare that they have no competing interests.

\section{Authors' contributions}

AN participated in all in vitro and in vivo experiments, including histologic analyses, and drafted and revised the manuscript. SM was responsible for the collection of samples of human adipose tissue, participated in all experiments involving animals, and revised the manuscript. NR participated in the isolation and culture of cell subsets, in the preparation of cells for flow cytometry, and revised the manuscript. FCU performed the analysis and interpretation of data from flow cytometry and drafted and revised the manuscript. MDM was responsible for the conception and design of the study, participated in all aspects of the study, including in vitro and in vivo experiments, performed the analysis and interpretation of data, and wrote the manuscript. All authors read and approved the final manuscript. All authors agree to be accountable for all aspects of the work in ensuring that questions related to the accuracy or integrity of any part of the work are appropriately investigated and resolved.

\section{Acknowledgements}

This work was supported by grants from Ministerio de Ciencia e Innovación (PI11/01242), Ministerio de Sanidad y Consumo (EMER07/005) and Consellería de Sanidad, Generalitat Valenciana (AP061/09 and AP069/10). We thank Elena Alvarez and Jordi Cerveró for their technical assistance.

\section{Author details}

${ }^{1}$ Regenerative Medicine Laboratory, Fundación Hospital General Universitario, 46014 Valencia, Spain. ${ }^{2}$ Department of Plastic and Reconstructive Surgery, Consorcio Hospital General Universitario, Valencia, Spain.

${ }^{3}$ Immunohematology Service, Centro de Transfusiones, Valencia, Spain.

Received: 3 December 2013 Revised: 4 March 2014

Accepted: 4 April 2014 Published: 14 April 2014

\section{References}

1. Zuk PA, Zhu M, Ashjian P, De Ugarte DA, Huang Jl, Mizuno H, Alfonso ZC, Fraser JK, Benhaim P, Hedrick MH: Human adipose tissue is a source of multipotent stem cells. Mol Biol Cell 2002, 13:4279-4295.

2. Crandall DL, Haussman GJ, Kral JG: A review of the microcirculation of adipose tissue: anatomic, metabolic, and angiogenic perspectives. Microcirculation 1997, 4:211-232.

3. Cao Y: Angiogenesis modulates adipogenesis and obesity. J Clin Invest 2007, 117:2362-2368. 
4. Shi Q, Rafii S, Wu MH, Wijelath ES, Yu C, Ishida A, Fujita Y, Kothari S, Mohle R, Sauvage LR, Moore MA, Storb RF, Hammond WP: Evidence for circulating bone marrow-derived endothelial cells. Blood 1998, 92:362-367.

5. Bailey AS, Willenbring $H$, Jiang $S$, Anderson DA, Schroeder DA, Wong MH, Grompe M, Fleming WH: Myeloid lineage progenitors give rise to vascular endothelium. Proc Natl Acad Sci U S A 2006, 103:13156-13161.

6. Neels JG, Thinnes T, Loskutoff DJ: Angiogenesis in an in vivo model of adipose tissue development. FASEB J 2004, 18:983-985.

7. Hausman GJ, Richardson RL: Adipose tissue angiogenesis. J Anim Sci 2004, 82:925-934

8. Rupnick MA, Panigrahy D, Zhang CY, Dallabrida SM, Lowell BB, Langer R, Folkman MJ: Adipose tissue mass can be regulated through the vasculature. Proc Natl Acad Sci U S A 2002, 99:10730-10735

9. Hutley $L$, Herington AC, Shurety W, Cheung C, Vesey DA, Cameron DP, Prins JB: Human adipose tissue endothelial cells promote preadipocyte proliferation. Am J Physiol Endocrinol Metab 2001, 281:E1037-E1044.

10. Fukumura D, Ushiyama A, Duda DG, Xu L, Tam J, Krishna V, Chatterjee K, Garkavtsev I, Jain RK: Paracrine regulation of angiogenesis and adipocyte differentiation during in vivo adipogenesis. Circ Res 2003, 93:e88-e97.

11. Curat CA, Miranville A, Sengenes C, Diehl M, Tonus C, Busse R, Bouloumié A: From blood monocytes to adipose tissue-resident macrophages: induction of diapedesis by human mature adipocytes. Diabetes 2004, 53:1285-1294.

12. Considine RV, Sinha MK, Heiman ML, Kriauciunas A, Stephens TW, Nyce MR, Ohannesian JP, Marco CC, McKee LJ, Bauer TL, Caro JF: Serum immunoreactive-leptin concentrations in normal-weight and obese humans. N Engl J Med 1996, 334:292-295.

13. Suganami E, Takagi H, Ohashi H, Suzuma K, Suzuma I, Oh H, Watanabe D, Ojima T, Suganami T, Fujio Y, Nakao K, Ogawa Y, Yoshimura N: Leptin stimulates ischemia-induced retinal neovascularization: possible role of vascular endothelial growth factor expressed in retinal endothelial cells. Diabetes 2004, 53:2443-2448

14. Weisberg SP, McCann D, Desai M, Rosenbaum M, Leibel RL, Ferrante AW Jr: Obesity is associated with macrophage accumulation in adipose tissue. J Clin Invest 2003, 112:1796-1808.

15. Sun K, Kusminski CM, Scherer PE: Adipose tissue remodeling and obesity. J Clin Invest 2011, 121:2094-2101.

16. Lumeng CN, Bodzin JL, Saltiel AR: Obesity induces a phenotypic switch in adipose tissue macrophage polarization. J Clin Invest 2007, 117:175-184.

17. Kim Y, Kim H, Cho H, Bae Y, Suh K, Jung J: Direct comparison of human mesenchymal stem cells derived from adipose tissues and bone marrow in mediating neovascularization in response to vascular ischemia. Cell Physiol Biochem 2007, 20:867-876

18. Matsuda K, Falkenberg KJ, Woods AA, Choi YS, Morrison WA, Dilley RJ: Adipose-derived stem cells promote angiogenesis and tissue formation for in vivo tissue engineering. Tissue Eng Part A 2013, 19:1327-1335.

19. Miñana MD, Carbonell-Uberos F, Mirabet V, Marín S, Encabo A: IFATS collection: identification of hemangioblasts in the adult human adipose tissue. Stem Cells 2008, 26:2696-2704

20. Planat-Benard V, Silvestre JS, Cousin B, André M, Nibbelink M, Tamarat R, Clergue M, Manneville C, Saillan-Barreau C, Duriez M, Tedgui A, Levy B, Pénicaud L, Casteilla L: Plasticity of human adipose lineage cells toward endothelial cells: physiological and therapeutic perspectives. Circulation 2004, 109:656-663.

21. Bhatia M, Wang JC, Kapp U, Bonnet D, Dick JE: Purification of primitive human hematopoietic cells capable of repopulating immune-deficient mice. Proc Natl Acad Sci U S A 1997, 94:5320-5325.

22. Rehman J, Traktuev D, Li J, Merfeld-Clauss S, Temm-Grove CJ, Bovenkerk JE, Pell $\mathrm{CL}$, Johnstone $\mathrm{BH}$, Considine RV, March KL: Secretion of angiogenic and antiapoptotic factors by human adipose stromal cells. Circulation 2004, 109:1292-1298.

23. Tigges U, Hyer EG, Scharf J, Stallcup WB: FGF2-dependent neovascularization of subcutaneous Matrigel plugs is initiated by bone marrow-derived pericytes and macrophages. Development 2008, 135:523-532.

24. van Schooten CJ, Shahbazi S, Groot E, Oortwijn BD, van den Berg HM, Denis CV, Lenting PJ: Macrophages contribute to the cellular uptake of von Willebrand factor and factor VIII in vivo. Blood 2008, 112:1704-1712.

25. Anghelina M, Krishnan P, Moldovan L, Moldovan Nl: Monocytes/ macrophages cooperate with progenitor cells during neovascularization and tissue repair: conversion of cell columns into fibrovascular bundles. Am J Pathol 2006, 168:529-541

26. Klein D, Weisshardt $P$, Kleff $V$, Jastrow $H$, Jakob HG, Ergün S: Vascular wall-resident $\mathrm{CD}_{4} 4^{+}$multipotent stem cells give rise to pericytes and smooth muscle cells and contribute to new vessel maturation. PLoS One 2011, 6:e20540.

27. Mokrý J, Ehrmann J, Karbanová J, Cízková D, Soukup T, Suchánek J, Filip S, Kolár Z: Expression of intermediate filament nestin in blood vessels of neural and non-neural tissues. Acta Medica (Hradec Kralove) 2008, 51:173-179.

28. Szöke K, Brinchmann JE: Concise review: therapeutic potential of adipose tissue-derived angiogenic cells. Stem Cells Transl Med 2012, 1:658-667.

29. Kuwana M, Okazaki Y, Kodama H, Izumi K, Yasuoka H, Ogawa Y, Kawakami Y, Ikeda Y: Human circulating CD14 ${ }^{+}$monocytes as a source of progenitors that exhibit mesenchymal cell differentiation. J Leukoc Biol 2003, 74:833-845.

30. Kuwana M, Okazaki Y, Kodama H, Satoh T, Kawakami Y, Ikeda Y: Endothelial differentiation potential of human monocyte-derived multipotential cells. Stem Cells 2006, 24:2733-2743.

31. Romagnani $P$, Annunziato F, Liotta F, Lazzeri E, Mazzinghi B, Frosali F, Cosmi L, Maggi L, Lasagni L, Scheffold A, Kruger M, Dimmeler S, Marra F, Gensini G, Maggi E, Romagnani S: CD14+ CD34low cells with stem cell phenotypic and functional features are the major source of circulating endothelial progenitors. Circ Res 2005, 97:314-322.

32. Conejo-Garcia JR, Buckanovich RJ, Benencia F, Courreges MC, Rubin SC, Carroll RG, Coukos G: Vascular leukocytes contribute to tumor vascularization. Blood 2005, 105:679-681.

33. Muller WA, Weigl SA, Deng X, Phillips DM: PECAM-1 is required for transendothelial migration of leukocytes. J Exp Med 1993, 178:449-460.

34. Ferrero E, Bondanza A, Leone BE, Manici S, Poggi A, Zocchi MR: CD14 ${ }^{+}$CD34 + peripheral blood mononuclear cells migrate across endothelium and give rise to immunostimulatory dendritic cells. J Immunol 1998, 160:2675-2683.

35. Asahara T, Murohara T, Sullivan A, Silver M, van der Zee R, Li T, Witzenbichler B, Schatteman G, Isner JM: Isolation of putative progenitor endothelial cells for angiogenesis. Science 1997, 275:964-967.

36. Urbich C, Dimmeler S: Endothelial progenitor cells: characterization and role in vascular biology. Circ Res 2004, 95:343-353.

37. Favre J, Terborg N, Horrevoets AJ: The diverse identity of angiogenic monocytes. Eur J Clin Invest 2013, 43:100-107.

38. Nowak G, Karrar A, Holmén C, Nava S, Uzunel M, Hultenby K Sumitran-Holgersson S: Expression of vascular endothelial growth factor receptor-2 or Tie-2 on peripheral blood cells defines functionally competent cell populations capable of reendothelialization. Circulation 2004, 110:3699-3707.

39. Wara AK, Croce K, Foo S, Sun X, Icli B, Tesmenitsky Y, Esen F, Rosenzweig A Feinberg MW: Bone marrow-derived CMPs and GMPs represent highly functional proangiogenic cells: implications for ischemic cardiovascular disease. Blood 2011, 118:6461-6464

40. Urbich C, Heeschen C, Aicher A, Dernbach E, Zeiher AM, Dimmeler S: Relevance of monocytic features for neovascularization capacity of circulating endothelial progenitor cells. Circulation 2003, 108:2511-2516.

41. Willenborg S, Lucas T, van Loo G, Knipper JA, Krieg T, Haase I, Brachvogel B, Hammerschmidt M, Nagy A, Ferrara N, Pasparakis M, Eming SA: CCR2 recruits an inflammatory macrophage subpopulation critical for angiogenesis in tissue repair. Blood 2012, 120:613-625.

42. Kim SJ, Kim JS, Papadopoulos J, Wook Kim S, Maya M, Zhang F, He J, Fan D, Langley R, Fidler IJ: Circulating monocytes expressing CD31: implications for acute and chronic angiogenesis. Am J Pathol 2009, 174:1972-1980.

43. Coffelt SB, Lewis CE, Naldini L, Brown JM, Ferrara N, De Palma M: Elusive identities and overlapping phenotypes of proangiogenic myeloid cells in tumors. Am J Pathol 2010, 176:1564-1576.

44. Grunewald M, Avraham I, Dor Y, Bachar-Lustig E, Itin A, Jung S, Chimenti S, Landsman L, Abramovitch R, Keshet E: VEGF-induced adult neovascularization recruitment, retention, and role of accessory cells. Cell 2006, 124:175-189.

45. Shojaei F, Wu X, Qu X, Kowanetz M, Yu L, Tan M, Meng YG, Ferrara N: G-CSF-initiated myeloid cell mobilization and angiogenesis mediate tumor refractoriness to anti-VEGF therapy in mouse models. Proc Nat Acad Sci U S A 2009, 106:6742-6747.

46. Eubank TD, Roberts R, Galloway M, Wang Y, Cohn DE, Marsh CB: GM-CSF induces expression of soluble VEGF receptor-1 from human monocytes and inhibits angiogenesis in mice. Immunity 2004, 21:831-842.

47. Bruno S, Bussolati B, Scacciatella P, Marra S, Sanavio F, Tarella C, Camussi G: Combined administration of G-CSF and GM-CSF stimulates monocytederived pro-angiogenic cells in patients with acute myocardial infarction. Cytokine 2006, 34:56-65. 
48. Augustin $\mathrm{HG}$, Koh GY, Thurston G, Alitalo K: Control of vascular morphogenesis and homeostasis through the angiopoietin-Tie system. Nat Rev Mol Cell Biol 2009, 10:165-177.

49. Felcht M, Luck R, Schering A, Seidel P, Hu J, Bartol A, Kienast Y, Vettel C, Loos EK, Srivastava K, Kutschera S, Bartels S, Appak S, Besemfelder E, Terhardt D, Chavakis E, Wieland T, Klein C, Thomas M, Uemura A, Goerdt S, Augustin HG: Angiopoietin-2 differentially regulates angiogenesis through TIE2 and integrin signaling. J Clin Invest 2012, 122:1991-2005.

50. Gimble JM, Bunnell BA, Chiu ES, Farshid G: Concise review: adipose-derived stromal vascular fraction cells and stem cells: let's not get lost in translation. Stem Cells 2011, 29:749-754.

doi:10.1186/scrt438

Cite this article as: Navarro et al:: Human adipose tissue-resident monocytes exhibit an endothelial-like phenotype and display angiogenic properties. Stem Cell Research \& Therapy 2014 5:50.

\section{Submit your next manuscript to BioMed Central and take full advantage of:}

- Convenient online submission

- Thorough peer review

- No space constraints or color figure charges

- Immediate publication on acceptance

- Inclusion in PubMed, CAS, Scopus and Google Scholar

- Research which is freely available for redistribution 